\title{
Modeling ground deformation associated with the destructive earthquakes occurring on Mt. Etna's southeastern flank in 1984
}

\author{
Flavio Cannavò ${ }^{1}$, Salvatore Gambino ${ }^{1}$, Biagio Puglisi ${ }^{2}$, and Rosanna Velardita ${ }^{2}$ \\ ${ }^{1}$ Istituto Nazionale di Geofisica e Vulcanologia, Osservatorio Etneo, Piazza Roma 2, Catania, Italy \\ ${ }^{2}$ Istituto Nazionale di Geofisica e Vulcanologia, Osservatorio Etneo, Via Monti Rossi, 95123 Nicolosi (CT), Italy \\ Correspondence to: Salvatore Gambino (salvatore.gambino@ingv.it)
}

Received: 10 November 2015 - Published in Nat. Hazards Earth Syst. Sci. Discuss.: 18 January 2016

Revised: 5 September 2016 - Accepted: 31 October 2016 - Published: 28 November 2016

\begin{abstract}
The Timpe Fault System is the source of very shallow but destructive earthquakes that affect several towns and villages on the eastern flank of Mt. Etna (Italy). In 1984, several seismic events, and specifically on 19 and 25 October, caused one fatality, 12 injuries and produced serious damage in the Zafferana and Acireale territories. This seismicity was mainly related to the activity of the Fiandaca Fault, one of the structures belonging to the Timpe Fault System.

We inverted ground deformation data collected by a geodimeter trilateration network set up in 1977 at a low altitude along the eastern side of the volcano in order to define the Timpe Fault System faulting mechanisms linked to the seismicity in 1984.

We have found that in the period May 1980-October 1984, the Fiandaca Fault was affected by a strike-slip and normal dip-slip of about 20.4 and $12.7 \mathrm{~cm}$ respectively. This result is kinematically consistent with field observations of the coseismic ground ruptures along the fault but it is notably large compared to displacements estimated by seismicity, then suggesting that most of the slip over the fault plane was aseismic.

The results once again confirm how seismicity and its relation with ground ruptures and creep displacement represent a very high hazard to the several towns and villages situated along the Timpe Fault System.
\end{abstract}

\section{Introduction}

The determination of finite fault geometry and slip for severe earthquakes is important for the mitigation of seismic hazard and in particular for very shallow earthquakes that entail surface fracturing.

On the eastern flank of Etna volcano, movements along very shallow normal faults generate recurrent seismicity sometimes leading to destructive events, since densely urbanized areas are located on these structures (e.g., Azzaro et al., 2012; Barreca et al., 2013c). The Timpe Fault System (TFS) (all the acronyms used from here on are reported in the Appendix) is the main source generating the strongest earthquakes known over the last 200 years (Azzaro et al., 2012).

The TFS dissects the southeastern flank of Mt. Etna (Fig. 1) and is formed by several fault segments that include the Fiandaca (FF), Santa Tecla (STF), Santa Venerina (SVF), Moscarello (MOF) and San Leonardello (SLF) faults (Figs. 1 and $2 b$ ), generally characterized by normal and right-lateral dynamics (Azzaro, 1999; Azzaro et al., 2000; Monaco et al., 1997).

The TFS shows right-lateral and normal dip-slip kinematics and each fault segment is characterized by earthquake related displacements of tens of centimeters and aseismic sliding behavior with slip rates of few millimeters per year (Bonforte et al., 2011; Azzaro, 2004; Monaco et al., 2010).

Shallow seismicity $(<3 \mathrm{~km})$, associated with these faults, includes the occurrence of several earthquakes with magnitude up to 4.5 (Azzaro et al., 2000) with epicenter in the fault areas. Despite their low-energy release, these events produced destructive effects, with fatalities and injuries, in a 


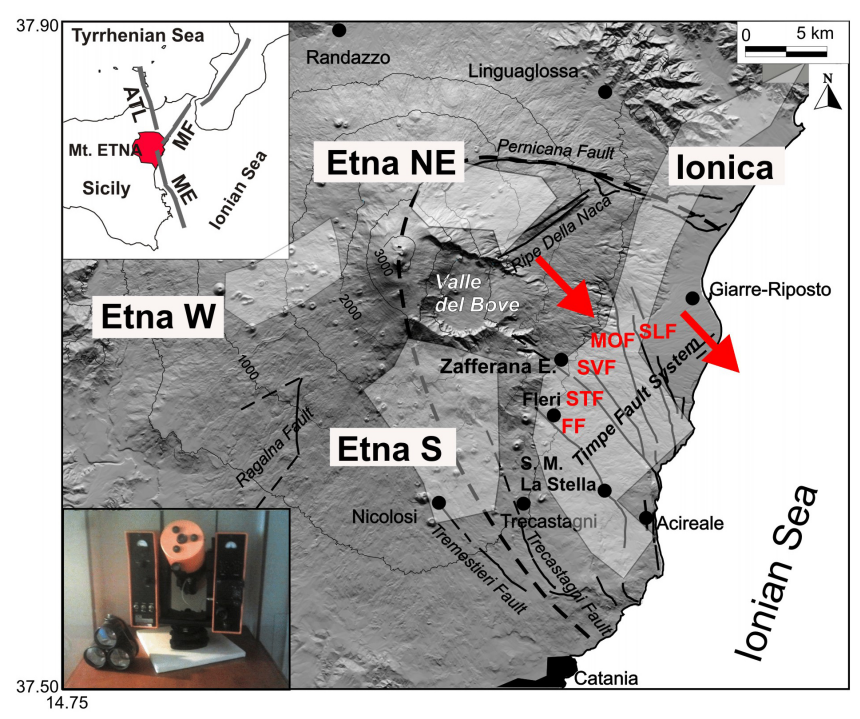

Figure 1. Surface faults map of Mt. Etna. Top inset map shows the main regional fault systems: MF is Messina-Fiumefreddo, ME is Malta Escarpment, and ATL is Aeolian-Tindari-Letojanni. Dashed line defines the sliding sector and red arrows indicate its movement direction. White areas are covered by EDM networks. In the bottom insert, the AGA 6BL laser geodimeter.

very narrow area where they can reach epicentral macroseismic intensity $I_{0}$ up to VIII/IX EMS (European macroseismic scale; Grünthal, 1998), often accompanied by coseismic surface fracturing (e.g., Azzaro, 1999, 2004) with a mean recurrence time of about 20 years (Azzaro et al., 2013b). The last destructive episodes with $I_{0}=$ VIII were recorded on 25 October 1984 and 29 October 2002. The first is the subject of this work while the second, linked to the SVF dynamics, caused damage at Santa Venerina village (Monaco et al., 2005; Azzaro et al., 2006; La Delfa et al., 2007).

During the second half of October 1984, an anomalous large number of seismic events, concentrated mostly on the eastern side of the volcano, were recorded on Mt. Etna (Gresta et al., 1987). The main events occurred in particular on 19 and 25 October 1984, with epicentral macroseismic intensity $I_{0}$ VII and VIII EMS, respectively, which struck the territory of Zafferana and specially the villages of Fleri and Pisano.

The 25 October earthquake was linked to the activity of the FF (Azzaro, 1999), while that on 19 October was located in proximity of the STF. In this paper, we exploit the slope distance measurements collected between 1977 and 1985 by a geodimeter trilateration network (Ionica network; Fig. 2a) set up in 1977 along the eastern edge of the volcano at low altitude (0-700 m b.s.l.) and measured until 1985 to shed new light on the kinematic aspects of this sequence of earthquakes. Indeed, the previously unpublished data, except for an internal report (Gruppo Nazionale per la Vulcanologia, 1985), have been reviewed in the wake of new knowl- edge acquired in the last two decades (described in the next section), enabling insights into Etna's eastern flank dynamics that were not possible at the acquisition time.

\section{Mt. Etna and its structural framework}

Mt. Etna (Fig. 1) is a large basaltic volcano built up in a geodynamic setting generated during the Neogene convergence between the African and European plates (e.g., Allard et al., 2006; Branca et al., 2011). It is situated on the eastern coast of Sicily and is one of the most active volcanoes in the world. Mt. Etna's activity may be grouped into two types: persistent activity comprising degassing phases alternating with strombolian activity, which may evolve into lava fountains and effusive events, and lateral flank eruptions occurring along fracture systems that are generally preceded by an intrusive process (e.g., Aloisi et al., 2006). The volcano is located at the intersection of two main regional fault systems, with NNW-SSE and NE-SW trends (Fig. 1). The NNW-SSE structural system represents the Sicilian onshore continuation of the Malta Escarpment Fault System (ME), the major crustal-scale fault separating the continental African platform from the oceanic Ionian Basin. Ripe Della Naca in Fig. 1 represents surface evidence related to NE-SW Messina-Fiumefreddo (MF) line, overlapping to the north with the ATL fault system (Palano et al., 2012, and references therein), while the faults of the "Timpe" system are the major tectonic surface manifestations of the ME. The interaction between regional stress, dike-induced rifting and gravity force is the cause of a fairly continuous and roughly eastward and downslope motion of its eastern flank (e.g., Puglisi and Bonforte, 2003; Solaro et al., 2010). Recent studies have investigated the interaction between flank deformation and local seismicity (Azzaro, 2004; Cannavò et al., 2015). This sliding area (Fig. 1) is delimited to the north by the Pernicana-Provenzana Fault System (PFS) (e.g., Obrizzo, 2001; Alparone et al., 2013a), a transtensive EW-trending complex active tectonic structure, while the Trecastagni, Tremestieri and Aci Trezza faults (e.g., Monaco et al., 2010; Bonforte et al., 2013) represent the main southern boundaries. The Mt. Etna GPS network has enabled us to determine how the entire eastern flank is affected by an ESE-ward motion, at a mean rate of about $1-3 \mathrm{~cm} \mathrm{yr}^{-1}$ (e.g., Bonforte et al., 2011; Gambino et al., 2011). Moreover, starting from 1980, the sliding area underwent two marked acceleration phases in October 1984-1986 and in October 20022005, as described in Alparone et al. (2013c). The authors also highlight a significant temporal correlation between periods of flank acceleration and intensified seismic activity.

It is worth noting that the Etna eastern flank is affected by earthquakes characterized by a strong attenuation of seismic energy in an orthogonal direction to the fault plane. This produces damage extending along narrow zones $(1-5 \mathrm{~km}$ long and up to $1 \mathrm{~km}$ wide) around the seismogenic source (Azzaro 


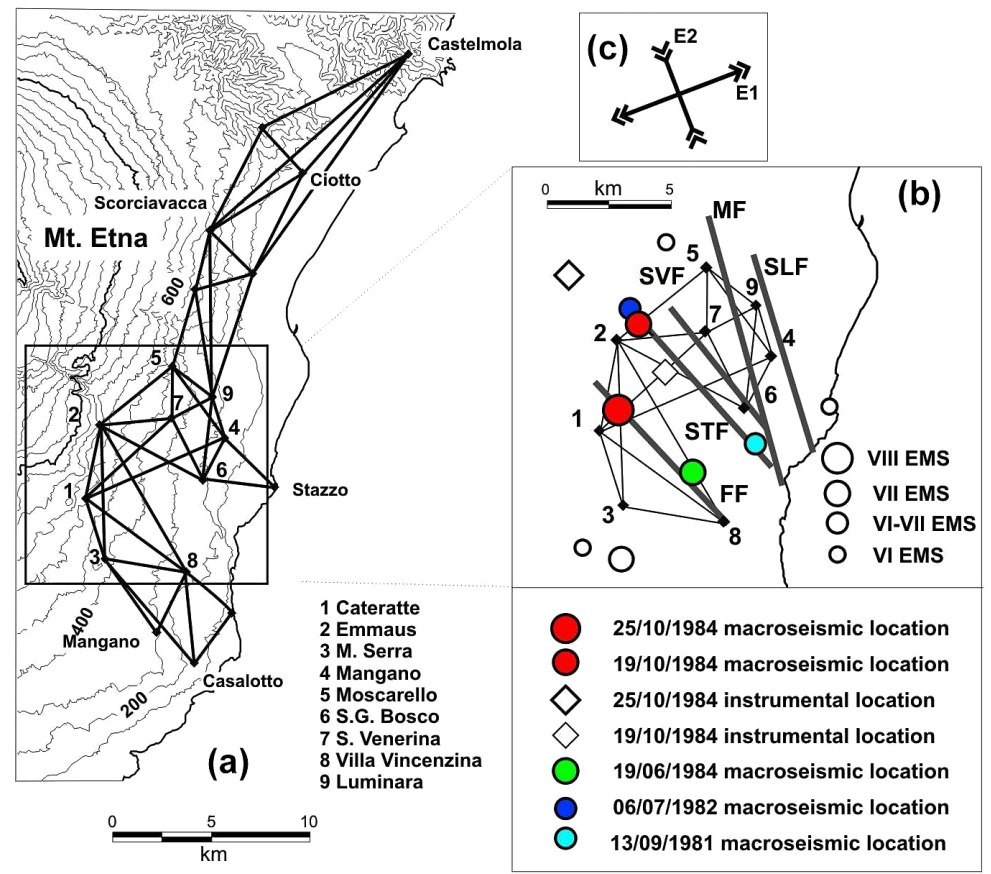

Figure 2. Ionica EDM network. (a) EDM benchmarks and lines measured between 1977 and 1985. (b) Macroseismic epicenters of earthquakes with epicentral intensities I0 $\geq$ VI EMS occurring from 1980 to October 1984 in the southeastern flank of Mt. Etna. (c) Principal strain axes obtained from the comparison of the overall measurement interval 1980-October 1984. FF is Fiandaca Fault, STF is Santa Tecla Fault, SVF is Santa Venerina Fault, MOF is Moscarello Fault, and SLF is San Leonardello Fault.

et al., 2006) and coseismic surface faulting effects, reported in detail in historical accounts, for the major seismic events.

The TFS is very active from the seismic point of view, both for the number of events and for maximum intensity reached at the epicenter (Azzaro et al., 2013a). TFS is characterized by surface faults of considerable length (up to $8-10 \mathrm{~km}$ ) and scarps (Monaco et al., 1997, 2010; Azzaro, 1999; Lanzafame et al., 1994). It includes (Fig. 2b) N140 E striking faults (FF, STF and SVF), which define normal right-lateral structures extending from the town of Acireale to Zafferana Etnea and the MOF and SLF faults with $\mathrm{N} 160^{\circ} \mathrm{E}$ structural trend that dissect the base of the volcano's flank by prevailingly vertical movements (Azzaro et al., 2013a).

The TFS plays a key role in the local tectonics accommodating the ESE seaward sliding (Azzaro et al., 2013a), the ME and MF motions and the edifice inflation/deflation episodes (Trasatti et al., 2009); this fault system divides the sliding sector into several blocks (Solaro et al., 2010; Bonforte et al., 2011) characterized by homogeneous kinematics with relative motion measured by permanent scatterers along the faults of about $3-5 \mathrm{~mm} \mathrm{yr}^{-1}$ in a "quiet" period such as 1995-2000 (Bonforte et al., 2011).

\section{Mt. Etna seismicity during 1984}

In October 1984, an intense seismic sequence was recorded on Mt. Etna area that marked an unusual behavior of the vol- cano. This swarm comprised more than 1000 earthquakes with $M>2.0$ over 2 weeks (16-30 October) and that involved the summit area and almost the entire eastern flank (Gresta et al., 1987; Gresta and Musumeci, 1997).

The main events (Fig. 2b) were on 19 (at 17:43 local time (LT)) and 25 October 1984 (at 01:12 LT), and struck the town of Zafferana and the Fleri and Pisano villages.

The earthquakes caused one fatality in Zafferana and injured 12 people in Fleri. In Fleri, the number of injuries would have been much higher, had most of the inhabitants, in great anxiety after an initial shock at around 22:00 LT the day before, not spent the night outdoors. Serious damage was caused to buildings in Zafferana but particularly in Fleri, which was almost entirely destroyed. About $70 \%$ of the buildings of the entire municipality (including all public buildings) were declared unfit for use (http://www.ct.ingv.it/ macro/etna/html_index.php).

In Fig. $2 b$ we report macroseismic and instrumental locations of the main seismic events between May 1980 and October 1984 (Table 1) in the TFS area. Given that the macroseismic epicenter is calculated as the barycenter of the data points with intensity $I=I_{0}, I_{0}-1$, the macroseismic location and the instrumental location may be rather different (Azzaro et al., 2000). Indeed Gresta et al. (1987), using a seismic network of just a few active stations in 1984, estimated a duration magnitude of 4.2 and 3.9 for the Zafferana and Fleri earthquakes, respectively, with different epicenters (Fig. 2b). 
Table 1. List of earthquakes recorded between May 1980 and October 1984 occurred in the investigated area (from Azzaro et al., 2000).

\begin{tabular}{llccclcc}
\hline & Date & Time $(\mathrm{UTC})$ & Longitude E $\left(^{\circ}\right)$ & Latitude N $\left(^{\circ}\right)$ & EMS & $M_{\mathrm{d}}$ & $M_{\mathrm{L}}$ \\
\hline 1 & $16 / 09 / 1980$ & $02: 30$ & 15.079 & 37.605 & VI & 2.9 & 3.0 \\
2 & $26 / 11 / 1980$ & $15: 04$ & 15.118 & 37.723 & VI & 3.1 & 3.3 \\
3 & $30 / 04 / 1981$ & $12: 32$ & 15.198 & 37.660 & VI & 3.5 & 3.7 \\
4 & $13 / 09 / 1981$ & $04: 49$ & 15.161 & 37.647 & VI-VII & 3.3 & 3.5 \\
5 & $06 / 07 / 1982$ & $14: 37$ & 15.104 & 37.698 & VI-VII & 3.8 & 4.1 \\
6 & $20 / 07 / 1983$ & $22: 03$ & 15.096 & 37.603 & VII & 4.1 & 4.4 \\
7 & $19 / 06 / 1984$ & $15: 19$ & 15.131 & 37.636 & VII & 3.4 & 3.6 \\
8 & $19 / 10 / 1984$ & $17: 43$ & 15.103 & 37.694 & VII & 4.2 & 4.5 \\
9 & $25 / 10 / 1984$ & $01: 11$ & 15.095 & 37.660 & VIII & 3.9 & 4.2 \\
\hline
\end{tabular}

For the two main events the Macroseismic Catalogue of Mt. Etna (CMTE Working Group, 2008) reports an $I_{0}$ of VII EMS for the 19 October event and of VIII EMS for the 25 October event.

In October 1984 more than $1.5 \mathrm{~km}$ long NW-SE trending cracks along the FF extended from the village of Fleri to SE with dip-slip displacements of about $20 \mathrm{~cm}$. It is worth noting that a similar ground rupture affected the southeastern part of FF during the VII EMS event of 19 June 1984 (Azzaro, 1999). NNW-SSE trending fractures that opened for several kilometers with prevailing extensional movement and rightlateral displacements of several centimeters occurred on FF also for earthquakes in 1875, 1894, 1907, 1914 and 1931 (Azzaro, 2004).

\section{The Ionica EDM network}

Between 1977 and 2002, the monitoring of the horizontal component of ground deformation at Mt. Etna was carried out by trilateration geodetic techniques using EDM (electro-optical distance measurements). Three separate networks were installed on the northeastern, western and southern flanks (Fig. 1).

A fourth EDM network (Ionica network) was installed and measured for the first time in October 1977 (Fig. 1), with the aim of verifying the possible relationships between the regional tectonic activity, highly evident in this area with the presence of numerous structures, and the volcanic activity (Fig. 2b).

The Ionica network was set up along the eastern edge of the volcano, along a line from Catania to Taormina, at low altitude (between $700 \mathrm{~m}$ and sea level); it consisted of 19 benchmarks and 43 lines, which were measured yearly from 1977 to May 1980.

The slope distances were recorded by using an AGA 6BL laser geodimeter (Fig. 1) and were corrected for atmospheric conditions considering temperature and atmospheric pressure values acquired at the measurement points. The instrumental error of such measurements is $5 \mathrm{~mm}$ plus $1 \mathrm{ppm}$ of the surveyed distance.
After the Zafferana and Fleri 1984 earthquakes, four measurement surveys were performed in the period October 1984-March 1985 in the portion of the network (Fig. 2b) covering the area affected by the events. The first survey was made between 26 and 31 October. These measurements involved only the southern part of the network, consisting of 9 benchmarks and 19 lines (Fig. 2b) with mean length of $4.7 \mathrm{~km}$.

\section{EDM data}

The results obtained from data collected from 1977 until 1985 indicate that the variations of distance with values greater than instrumental error occurred mainly in the period May 1980-October 1984, while distance variations obtained from the comparison with the other surveys are mainly within the error. In particular, changes are up to $108 \mathrm{~mm}$ and ten measurements showed variations over $50 \mathrm{~mm}$ (Fig. 3). In the previous period (1977-1980), the changes observed are generally within the instrumental error though a trend is detectable for several lines. In a first analysis, we studied the strain of the area in the considered period.

Ground deformation strain field is given by the uniform strain tensor components $\varepsilon_{i j}$, which can be calculated by using variations of slope distances (Jaeger, 1969):

$$
\Delta L_{\mathrm{MN}} / L_{\mathrm{MN}}=\varepsilon_{11} \cos ^{2} \delta_{\mathrm{MN}}+\varepsilon_{22} \sin ^{2} \delta_{\mathrm{MN}}+\varepsilon_{12} \sin 2 \delta_{\mathrm{MN}},
$$

where $\Delta L_{\mathrm{MN}}$ is the change in length of the line MN (with length $L_{\mathrm{MN}}$ ) between two points $\mathrm{M}$ and $\mathrm{N}$ and $\delta_{\mathrm{MN}}$ is the angle between MN direction and $x$ axis. The deformation computed in this way is the "equivalent" uniform deformation providing the same distance variations as the real nonuniform deformation, concentrated on the faults.

This tensor indicates the average deformation occurring between two different surveys in the area covered by the network and provides useful information on the ground deformation regime of the area (e.g., Bonaccorso, 2002). We calculated the principal strain axes (Fig. 2c) drawn from the comparison of the overall measurement interval $1980-$ October 1984 . We obtained a positive extension $\left(\varepsilon_{1}=17 \pm 4.4 \mu\right.$ strain $)$ oriented approximately orthogonal to 
Table 2. Best fitting range for the model.

\begin{tabular}{lll|ll}
\hline & \multicolumn{2}{c}{ Fault 1(FF) } & \multicolumn{2}{c}{ Fault 2 (STF) } \\
\cline { 2 - 5 } Parameter (unit) & Assumed range & Best-fit solution & Assumed range & Best-fit solution \\
\hline$X$ (m, center top) & Fixed & 509700 & Fixed & 512423 \\
$Y(\mathrm{~m}$, center top) & Fixed & 4166660 & Fixed & 4168595 \\
Depth (m, top) & Fixed & 0 & Fixed & 0 \\
Azimuth $\left(^{\circ}\right)$ & Fixed & 140 & Fixed & 142 \\
\hline Dip $\left(^{\circ}\right)$ & $70 \div 89.9$ & $70 \pm 0.0$ & $70 \div 89.9$ & $70 \pm 0.0$ \\
Semi-length (m) & $2000 \div 3500$ & $3500 \pm 1200$ & $2000 \div 4000$ & $2000 \pm 0.0$ \\
Width (m) & $1000 \div 3000$ & $3000 \pm 0$ & $1000 \div 3000$ & $2572 \pm 1100$ \\
Strike-slip (cm) & $0 \div 100($ dextral) & $20.4 \pm 1.6$ & $0 \div 100($ dextral) & $0.0 \pm 0.0$ \\
Dip-slip (cm) & $-100 \div 0$ (normal) & $-12.7 \pm 2.6$ & $-100 \div 0$ (normal) & $-10.4 \pm 5.7$ \\
\hline
\end{tabular}

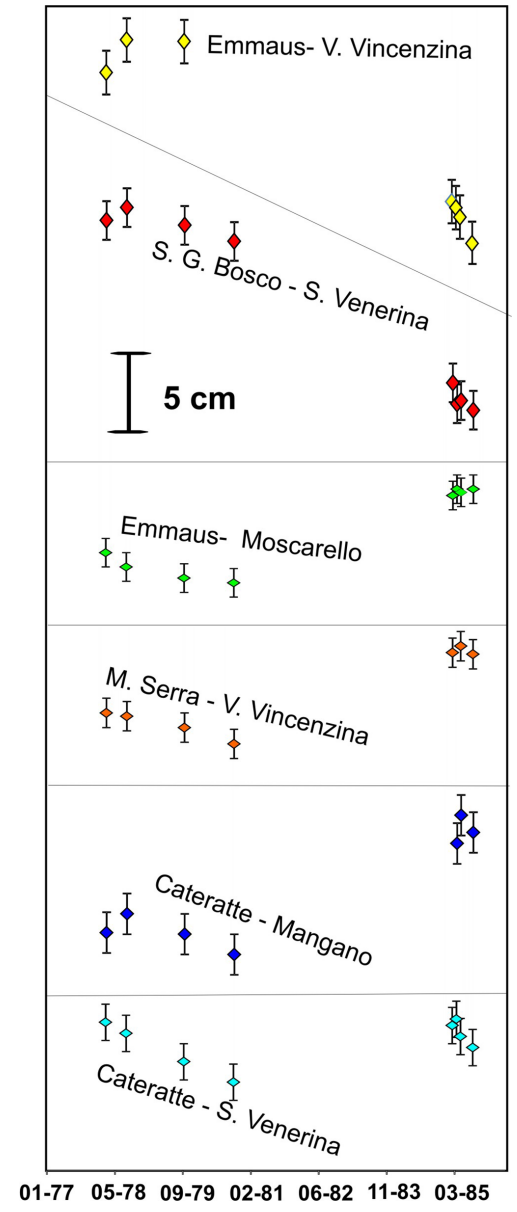

Figure 3. Changes of measured line lengths with respect to time of surveying time (interval 1977-1985) in the Ionica network. Note how the lines are subject to marked variations in the 1980-1984 period. and a contraction $\left(\varepsilon_{2}=-12.2 \pm 4.4 \mu\right.$ strain $)$ parallel to the FF and STF fault systems (Fig. 2).

\section{Geodetic data modeling}

In a further study, the ground deformation field for the 19801984 interval was used as input to constrain isotropic halfspace elastic inversion models using Okada's (1992) model. The aim of this inversion is to characterize the FF and STF dynamics during this particular period. Unlike in 1985, several of the geometric parameters of the two considered faults are known today (Azzaro et al., 2013b). Thus, the reduction of the number of unknowns has allowed us to make a constrained inversion of the relatively small EDM dataset. In particular, we fixed the more reliable parameters (Table 1), while for the more dubious ones (less precise) we chose to leave them to be free (constrained to a range) during the inversion together with the kinematic parameters.

To model the displacements due to each single fault, we adopted the analytical model described in Okada (1992), and to take the simultaneously effects of two (or more) faults into account we used the superposition principle. The Okada equations give the 3 -D displacement $\left(\delta_{P}\right)$ at a point $P$ due to the fault geometry and its kinematic. For a baseline between the points $P_{i}$ and $P_{j}$, we modeled the EDM distance variation as

$\Delta_{i j}=\left\|\left(P_{i}+\delta_{P_{i}}\right)-\left(P_{j}+\delta_{P_{j}}\right)\right\|-\left\|P_{i}-P_{j}\right\|$,

where $\|\cdot\|$ is the 3-D Euclidean norm operator.

In particular, we inverted for the parameters reported in gray in Table 2, where the associated ranges are also shown. These values are estimations, calculated from geophysical, geological and historical data; however, not all parameters are available. We excluded all the lines crossing the MOF. Thus we had a total of 10 free parameters and 13 EDM measurements. It is worth noting in Table 2 that five free parameters reach an extreme in their feasible ranges. Hence, they could be treated as fixed parameters and set to their maxi- 


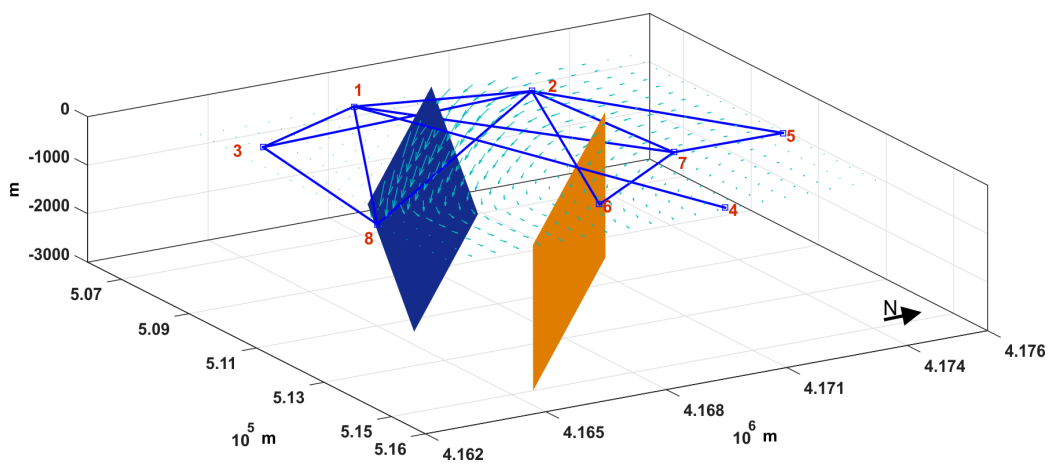

Figure 4. Location and E-W cross section of the source modeled. The arrows represent the simulated deformation field due to the estimated fault kinematics. Reference numbers as in Fig. 2.

mum/minimum possible values, thus reducing the degrees of freedom in the inverse problem. We considered a shear modulus of $10 \mathrm{GPa}$ and a Poisson's ratio of 0.25 (e.g., Bozzano et al., 2013).

In order to estimate simultaneously the free geometric parameters and kinematics of both the considered faults, we inverted the EDM data by minimizing the weighted misfit between the measured and calculated distances. Because of the free geometric parameters, the mathematical problem is nonlinear and the adopted minimization algorithm was a hybrid approach of genetic algorithm and pattern search (Audet and Dennis, 2002). The measurements were weighted with their associated instrumental errors expressed in meters by the following formula:

$\sigma_{\Delta_{i j}}=\sqrt{2}\left(0.005+10^{-6}\left\|P_{i}-P_{j}\right\|\right)$.

The square root of 2 is due to the error propagation in calculating the distance variation $\Delta_{i j}$ neglecting the displacement.

The modeled displacements and their associated uncertainties were used to perform a goodness-of-fit test (chisquared test) in order to assess the inversion reliability for the given data (Taylor, 1997). The found model fits the EDM data with a reduced chi-square $\left(\chi_{\text {red }}^{2}\right)$ of 0.95 , thus indicating that the extent of the match between measurements and estimates is in accord with the error variance.

A jackknife re-sampling method (Efron, 1982) was used to estimate the error of model parameters. The technique requires several optimization executions, each one deprived of just one measurement in input. The errors at $99 \%$ are estimated as 3 times the standard deviation in the set of the found solutions.

The results (Table 2 and Fig. 4) are in agreement with the dominant faulting style producing a normal strike-slip movement with $20.4 \mathrm{~cm}$ of dextral strike movement and $12.7 \mathrm{~cm}$ of normal dip on FF, while we obtained $10.4 \mathrm{~cm}$ of normal dip on STF. A comparison between observed and modeled slope distance is reported in Fig. 5.

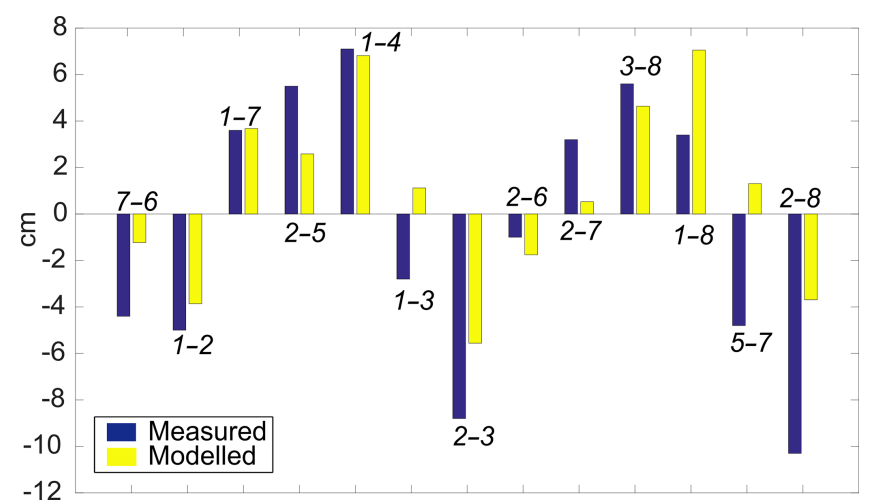

Figure 5. Comparison between observed (blue bars) and modeled (yellow bars) slope distance. Numbers as in Fig. 2. It can be noticed that the worst fit occurs for baselines not crossing any fault.

\section{Sensitivity analysis}

We carried out a sensitivity analysis in order to ascertain whether our data could constrain a valid set of fault parameters. We adopted the Sobol' analysis (Sobol', 1990), a variance-based global method to measure sensitivity across the whole input space, dealing with nonlinear responses and estimating the effect of interactions in nonadditive systems. The method breaks the variance of the output of the model down into fractions (normalized to 1) which can be attributed (in percentage) to input terms. The Sobol' first-order indices indicate the contribution of the main effect of each input parameter to the output variance, therefore measuring the effect of varying the input parameter alone, averaged over variations in other input parameters. We adopted the algorithm in Cannavò (2012) to calculate the first-order Sobol' indices of all the fault parameters given in our EDM data. The indices reported in Table 3 represent the fraction of variance in the data that can be attributed to each fault parameter. The higher the fraction, the more constrained is the parameter by the data. Results show that, among all the parameters, the data are more sensitive to strike-slips and mainly to fault lengths 
Table 3. Global sensitivity analysis. First-order Sobol' coefficients for the fault parameters and total sums. Bold numbers represent the paramenters to which the data are predominally sensitive.

\begin{tabular}{lccc}
\hline $\begin{array}{l}\text { Parameter } \\
\text { (unit) }\end{array}$ & $\begin{array}{c}\text { Fault 1 } \\
(\mathrm{FF})\end{array}$ & $\begin{array}{c}\text { Fault 2 } \\
(\mathrm{STF})\end{array}$ & TOTAL \\
\hline Dip ( ${ }^{\circ}$ ) & 0.003 & 0.006 & 0.009 \\
Semi-length (m) & $\mathbf{0 . 2 3 7}$ & 0.022 & 0.259 \\
Width (m) & 0.028 & 0.004 & 0.032 \\
Strike-slip (m) & $\mathbf{0 . 1 6 8}$ & 0.054 & 0.222 \\
Dip-slip (m) & 0.072 & 0.002 & 0.074 \\
\hline TOTAL & 0.508 & 0.088 & \\
\hline
\end{tabular}

for FF fault, which, in turn, can be estimated more accurately than the other parameters.

\section{Discussion and conclusions}

The TFS dissect the Mt. Etna's lower eastern flank. It is formed of several segments (FF, STF, SVF, SLF and MOF) that show right-lateral kinematics and normal dip-slip with slip rates ranging from 3.0 to $5.0 \mathrm{~mm} \mathrm{yr}^{-1}$ during "quiet" periods (Bonforte et al., 2011).

Timpe dynamics are linked to the ESE-ward motion of the eastern flank of Mt. Etna (e.g., Azzaro, 2013a). Since 1980, the ESE-ward motion of this flank has shown two phases of increased velocity, the first being observed in the October 1984-1987 period (Alparone et al., 2013c).

Severe/destructive events, with a mean recurrence time of about 20 years according to Azzaro et al. (2013c), make the TFS extremely important in terms of seismic hazard.

These events are distributed on the several segments and in the last decades the destructive episodes have affected FF in October 1984 and SVF in October 2002.

The 25 October 1984 event (with $M_{\mathrm{d}}=3.9$ ) most likely represents the strongest event recorded on FF since 1875 (Azzaro et al., 2004). In this context, we tried to characterize the finite fault geometry and slip of FF by ground deformation observations. We recovered and analyzed the EDM measurements of the Ionica network crossing the TFS and measured only between 1977 and 1985. These data highlight major variations between 1980 and 1984; the principal components of the strain tensor obtained in this period show a positive extension oriented approximately orthogonal and a negative extension parallel to the FF and STF fault systems and are consistent with normal right-lateral dynamics of the two structures.

We inverted data showing that, between 1980 and November 1984, the FF ( $7 \mathrm{~km}$ length and $2.6 \mathrm{~km}$ depth) was affected by a strike-slip component of $20.4 \pm 1.6 \mathrm{~cm}$ and a normal dip-slip of $12.7 \pm 2.6 \mathrm{~cm}$ (overall displacement ca. $24 \mathrm{~cm}$ ). The sensitivity analysis indicates that fault length and strike- slip represent the most accurately constrained parameter obtained by data inversion.

In consideration of the inversion results, and assuming a medium rigidity $\mu=10 \mathrm{GPa}$ in the general relation $M=\mu$. $S \cdot \bar{u}$ (Aki, 1966), we obtained a geodetic moment $M_{\mathrm{G}}=$ $4.4 \times 10^{23}$ dyne-cm.

An estimate of the seismic moment release associated with the seismic events was obtained using the following relation (Giampiccolo et al., 2007) for Etnean earthquakes:

$\log (\mathrm{Mo})=(17.60 \pm 0.37)+(1.12 \pm 0.10) \cdot M_{\mathrm{L}}$,

where $M_{\mathrm{L}}$ is the local magnitude.

Duration magnitude $\left(M_{\mathrm{d}}\right)$ of 19 June and 25 October 1984 earthquakes was estimated as 3.4 and 3.9 (Table 1); we converted $M_{\mathrm{d}}$ into local magnitude (obtaining 3.6 and 4.2 respectively) by using the Tuvè et al. (2015) relation:

$M_{\mathrm{L}}=1.164( \pm 0.011) \cdot M_{\mathrm{d}}-0.337( \pm 0.020)$,

obtaining for $\mathrm{Mo}$, respectively, $5 \times 10^{21}$ dyne-cm and $2 \times 10^{22}$ dyne-cm; moreover Mo cannot be greater than $2.4 \times 10^{22}$ dyne-cm for the $M_{\mathrm{d}}=3.419$ June earthquake and $1.2 \times 10^{23}$ dyne-cm for the $M_{\mathrm{d}}=3.925$ October earthquake.

Therefore, only a part (from $5 \%$ to a maximum of $30 \%$ ) of the kinematics obtained by modeling is related to the coseismic effects of the earthquakes recorded along the FF, suggesting that most of the slip over the fault must be aseismic. These results are similar to those obtained by Obrizzo et al. (2001) for the PFS after analyzing 17 years of leveling data. These authors concluded that only $30 \%$ of the total deformation of PFS is attributable to coseismic displacements.

The assumption on which the paper is based is that the measured deformation field is mostly accomplished through seismic and aseismic slip over recognized faults during the 1980-1984 period; the seismic contribution is found to be only a minor fraction and field measurements on FF show that the aseismic contribution anticipated the October 1984 seismic sequence. The misfit of EDM lines which do not cross any fault may be plausibly ascribed to pervasive plastic deformation or to no uniform slip over the fault surface.

Few variations have been detected on the STF, which seems to have been little affected by the October 1984 dynamics. The $M_{\mathrm{d}}=3.419$ June event does actually appear to be located at the northern edge of the fault (Gresta et al., 1987). The model estimated no significant strike-slip and a $10.4( \pm 5.7) \mathrm{cm}$ dip-slip on STF. In consideration of weak constrain due to the very low sensitivity of the STF dipslip parameter for the used dataset (Table 3) and magnitude of the October 19 event $\left(M_{\mathrm{d}}=4.2, M_{\mathrm{L}}=4.5\right.$; Table 1$)$, we infer that no significant shifts of the STF occurred in October 1984. Moreover precise locations of the earthquakes $\left(M_{\mathrm{dmax}}=3.7\right)$ recorded in the same area between 1995 and 2006 (Alparone and Gambino, 2003; Alparone et al., 2013b) have shown that the seismicity in this sector is generally 3 $5 \mathrm{~km}$ b.s.l. deep and related to NE-SW oriented seismogenic 
structures (MF line). For all these reasons, we retain that the $M_{\mathrm{d}}=4.219$ October event is not attributable to STF dynamics.

To summarize, the destructive $M_{\mathrm{d}}=3.925$ October 1984 event is an effect of an important dynamic episode that affected the FF structure timely related with a flank acceleration phase (Alparone et al., 2013c). EDM data inversion indicated a total stick-slip of ca. $24 \mathrm{~cm}$ between 1980 and 1984, mainly between June and October 1984 along a fault length of $7 \mathrm{~km}$. This result is comparable with field observations that detected ground ruptures (coseismic and aseismic) of the northwestern and southeastern sectors of the fault of up to $20 \mathrm{~cm}$ (Azzaro, 1999, and reference therein). The discrepancy between the seismic and geodetic moment allows us to quantify the amount of aseismic deformation. Indeed, FF shows a low seismic efficiency (lower than $30 \%$ ), a feature that seems common to other very shallow faults on the eastern flank (e.g., the PFS) and that highlights that most of the energy is involved in aseismic ground displacements.

We think that the ground rupture that affected the southeastern part of FF (on occasion of the VII EMS event of 19 June 1984) represents the first phase of a process that involved the entire FF on 25 October 1984. Indeed, a northwards "migration" of the rupture sequence was suggested by Azzaro (1999) and our model is in accordance with this hypothesis showing that the entire FF was activated (even if data do not allow us to discern the time-space sequence). This rupture process marked the beginning of the acceleration phase of all eastern flank dynamics (Alparone et al., 2013c) that persisted for about 3 years (1984-1987). A similar behavior also happened for the destructive 29 October 2002 event that occurred on SVF at the beginning of the second phase of flank acceleration (October 2002-onward; Alparone et al., 2013c).

Finally, these considerations again confirm the high level of geological hazard (embracing both the hazard due to seismic shaking effects and the one due to ground rupture effects) of the FF and generally of the Timpe Fault System, for the several towns and villages located on these structures.

\section{Data availability}

The data is available at: http://www.ct.ingv.it/utenti/ gambino/EDM_data.xlsx. 
Appendix A: List of the used acronyms.

$\begin{array}{ll}\text { TFS } & \text { Timpe Fault System } \\ \text { FF } & \text { Fiandaca fault } \\ \text { STF } & \text { Santa Tecla fault } \\ \text { SVF } & \text { Santa Venerina fault } \\ \text { MOF } & \text { Moscarello fault } \\ \text { SLF } & \text { San Leonardello fault } \\ \text { ME } & \text { Malta Escarpment fault system } \\ \text { MF } & \text { Messina-Fiumefreddo line } \\ \text { EMS } & \text { European macroseismic scale } \\ \text { EDM } & \text { Electro-optical distance measurements } \\ M_{\mathrm{G}} & \text { Geodetic moment (dyne-cm) } \\ \text { Mo } & \text { Seismic moment (dyne-cm) } \\ M_{\mathrm{L}} & \text { Local magnitude } \\ M_{\mathrm{d}} & \text { Duration magnitude }\end{array}$


Acknowledgements. We are indebted to Letterio Villari who, since the 1970s, understood the importance of monitoring Etna's eastern flank and who planned and worked to set up the Ionica EDM network.

We thank Maurizio Bonafede and an anonymous referee for their critical reading of the manuscript and constructive comments, which helped us to improve the paper. We also thank Stephen Conway for correcting and improving the English language of this paper.

Edited by: B. D. Malamud

Reviewed by: M. Bonafede and one anonymous referee

\section{References}

Aki, K.: Generation and propagation of $\mathrm{G}$ waves from Niigata earthquake of June 16, 1964, II, Estimation of earthquake moment, released energy, and stress-strain drop from the $\mathrm{G}$ wave spectrum, Bull. Earthquake Res. Inst. Univ. Tokyo, 44, 73-88, 1966.

Allard, P., Behncke, B., D'Amico, S., Neri, M., and Gambino, S.: Mount Etna 1993-2005: anatomy of an evolving eruptive cycle, Earth-Sci. Rev., 78, 85-114, doi:10.1016/j.earscirev.2006.04.002, 2006.

Aloisi, M., Bonaccorso, A., and Gambino, S.: Imaging compositive dike propagation (Etna, 2002 case), J. Geophys. Res., 111, B06404, doi:10.1029/2005JB003908, 2006.

Alparone, S. and Gambino, S.: High precision locations of multiplets on south-eastern flank of Mt. Etna (Italy): reconstruction of fault plan geometry, Phys. Earth Planet. Int., 135, 281-289, 2003.

Alparone, S., Cocina, O., Gambino, S., Mostaccio, A., Spampinato, S., Tuvè, T., and Ursino, A.: Seismological features of the Pernicana-Provenzana fault system and implications for the dynamics of northeastern flank of the volcano, J. Volcanol. Geotherm Res., 251, 16-26, doi:10.1016/j.jvolgeores.2012.03.010, 2013a.

Alparone, S., D’Amico, S., Gambino, S., and Maiolino, V.: Buried active faults in the Zafferana Etnea territory (south-eastern flank of Mt. Etna): geometry and kinematics by earthquake relocation and focal mechanisms, Ann. Geophys., 56, R0112, doi:doi:10.4401/ag-5758, 2013b.

Alparone, S., Bonaccorso, A., Bonforte, A., and Currenti, G.: Longterm stress-strain analysis of volcano flank instability: The eastern sector of Etna from 1980 to 2012, J. Geophys. Res.-Earth, 118, 5098-5108, doi:10.1002/jgrb.50364, 2013c.

Audet, C. and Dennis Jr., J. E.: Analysis of generalized pattern searches, SIAM J. Optimiz., 13, 889-903, 2002.

Azzaro, R.: Earthquake Surface Faulting At Mount Etna Volcano (Sicily) And Implications For Active Tectonics, J. Geodyn., 28, 193-213, 1999.

Azzaro, R., Barbano, M. S., Antichi, B., and Rigano, R.: Macroseismic catalogue of Mt. Etna earthquakes from 1832 to 1998, Ac. Vulcanol., 12, 3-36, 2000.

Azzaro, R.: Seismicity and active tectonics in the Etna region: constraints for a seismotectonic model, in: Mt. Etna: volcano laboratory, edited by: Bonaccorso, A., Calvari, S., Coltelli, M., Del Negro, C., and Falsaperla, S., American Geophysical Union, Geophys. Monogr., 143, 205-220, 2004.
Azzaro, R., D’Amico, S., Mostaccio, A., Scarfî, L., and Tuvè, Y.. Terremoti con effetti macrosismici in Sicilia Orientale - Calabria Meridionale nel periodo Gennaio 2002-Dicembre 2005, Quad. Geofis., 41, 1-60, 2006.

Azzaro, R., D’Amico, S., Peruzza, L., and Tuvè, T.: Earthquakes and faults at Mt. Etna:problems and perspectives for a timedependent probabilistic seismic hazard assessment in a volcanic region, B. Geofis. Theor. Appl., 1, 75-88, 2012.

Azzaro R., Bonforte, A., Branca, S., and Guglielmino, F.: Geometry and kinematics of the fault systems controlling the unstable flank of Etna volcano (Sicily), J. Volc. Geotherm. Res., 251, 515, 2013a.

Azzaro R., D’Amico, S., Rotondi, R., Tuvè, T., and Zonno, G.: Forecasting seismic scenarios on Etna volcano (Italy) through probabilistic intensity attenuation models: a Bayesian approach, J. Volc. Geotherm. Res., 251, 149-157, 2013b.

Azzaro, R., D’Amico, S., Peruzza, L., and Tuvè, T.: Probabilistic seismic hazard at Mt. Etna(Italy): the contribution of local fault activity in mid-term assessment, J. Volc. Geotherm. Res., 251, 158-169, 2013c.

Bonaccorso, A.: Ground deformation of the southern sector of the Aeolian islands volcanic arc from geodetic data, Tectonophysics, 351-353, 181-192, 2002.

Bonforte, A. and Puglisi G.: Magma uprising and flank dynamics on Mt. Etna volcano, studied by GPS data (1994-1995), J. Geophys. Res., 108, 2153-2162, 2003.

Bonforte, A., Guglielmino, F., Coltelli, M., Ferretti, A., and Puglisi, G.: Structural assessment of Mt. Etna volcano from Permanent Scatterers analysis, Geochem Geophy. Geosy., 12, Q02002, doi:10.1029/2010GC003213, 2011.

Bonforte, A., Carnazzo, A., Gambino, S., Guglielmino, F., Obrizzo, F., and Puglisi, G.: The Trecastagni Fault (Mt. Etna, Italy): a multidisciplinary study by continuous, discrete and satellite ground deformation measurements, J. Volcanol. Geotherm Res., 251, 42-50, 2013.

Bozzano, F., Gaeta, M., Lenti, L., Martino, S., Paciello, A., Palladino, D. M., and Sottili, G.: Modeling the effects of eruptive and seismic activities on flank instability at Mount Etna, Italy, J. Geophys. Res.-Earth, 118, 5252-5273, 2013.

Branca, S., Coltelli, M., and Groppelli, G.: Geological evolution of a complex basaltic stratovolcano: Mount Etna, Italy, Ital. J. Geosci., 130, 306-317, 2011.

Cannavó, F.: Sensitivity analysis for volcanic source modeling quality assessment and model selection, Comp. Geosci., 44, 52-59, 2012.

Cannavò, F., Arena, A., and Monaco, C.: Local geodetic and seismic energy balance for shallow earthquake prediction, J. Seismol., 19, 1-8, doi:10.1007/s10950-014-9446-z, 2015.

CMTE Working Group: Catalogo Macrosismico dei Terremoti Etnei, 1832-2008, INGV, Catania, available at: http://www.ct.ingv. it/macro/etna/html_terremoto.php, 2008.

Efron, B.: The Jacknife, Bootstrap and Other Resampling Plans, Philadelphia, Society for Industrial and Applied Mathematics, 91 pp., 1982.

Gambino, S., Bonforte, A., Carnazzo, A., Falzone, G., Ferrari, F., Ferro, A., Guglielmino, F., Laudani, G., Maiolino, V., and Puglisi, G.: Displacement across the Trecastagni Fault (Mt. Etna) and induced seismicity: the October 2009-January 2010 episode, Ann. Geophys., 54, 414-423, 2011. 
Giampiccolo, E., D’Amico, S., Patanè, D., and Gresta, S.: Attenuation and source parameters of shallow microearthquakes at Mt. Etna Volcano, Italy, Bull. Seismol. Soc. Am., 97, 184-197, doi:10.1785/0120050252, 2007.

Gresta, S. and Musumeci, C.: Stress tensor computation from earthquake fault-plane solutions: an application to seismic swarms at Mt. Etna volcano (Italy), Annali di Geofisica, XL, 5, 1250-1260, 1997.

Gresta, S., Glot, J. P., Patanè, G., Poupinet, G., and Menza, S.: The October seismic crisis at Mount Etna. Part I: Space-Time evolution of events, Ann. Geophys., 5B, 671-680, 1987.

Gruppo Nazionale per la Vulcanologia: Rapporto trimestrale sullo stato dell'attività nell'area etnea, Trimestre ottobre-dicembre 1984, Unità di ricerca dell'Istituto Internazionale di Vulcanologia, CNR e dell'Istituto di Scienze della terra, Università di Catania, 26 pp., 1985.

Grünthal, G. (Ed.): European macroseismic scale 1998 (EMS-98). European Seismological Commission, subcommission on Engineering Seismology, working Group Macroseismic Scales, Conseil de l'Europe, Cahiers du Centre Européen de Géodynamique et de Séismologie, 15, Luxembourg, 99 pp., 1998.

Jaeger, J. C.: Elasticity, Fracture and Flow. With Engineering and Geological Applications. Chapman \& Hall, London, 268 pp., 1969.

La Delfa, S., Patanè, G., Presti, F., and Tringali, G.: Changing in crust mechanical behaviour due to raising magma: a fracturing model of SE flank of Mt Etna (Sicily), Earth Planet. Sci. Lett., 256, 493-509, 2007.

Lanzafame, G., Neri, M., and Rust, D.: Active tectonics affecting the eastern flank of Mount Etna: structural interactions at a regional and local scale, in: Etna: fifteen years on Etna: Fifteen Years On, edited by: Gravestock, P. J. and Mc Guire, W. J., Cheltenham and Gloucester Special Publication, 25-33, 1994.

Monaco, C., Tapponnier, P., Tortorici, L., and Gillot, P. Y.: Late Quaternary slip-rates on the Acireale-Piedimonte fault system and tectonic origin of Mt. Etna, Earth Planet. Sc. Lett., 147, 125139, 1997.
Monaco, C., Catalano, S., Cocina, O., De Guidi, G., Ferlito, C., Gresta, S., Musumeci, C., and Tortorici, L.: Tectonic control on the eruptive dynamics at Mt. Etna volcano (eastern Sicily) during the 2001 and 2002-2003 eruptions, J. Volc. Geoterm. Res., 144, 221-233, 2005.

Monaco, C., De Guidi, G., and Ferlito, C.: The morphotectonic map of Mt. Etna, Boll. Soc. Geol. It., 129, 408-428, 2010.

Obrizzo, F., Pingue, F., Troise, C., and De Natale, G.: Coseismic displacements and creeping along Pernicana fault (Mt. Etna) in the last seventeen years: a detailed study of a structure on a volcano, J. Volcanol. Geotherm. Res., 9, 109-131, 2001.

Okada, Y.: Internal deformation due to shear and tensile faults in a half-space, Bull. Seismol. Soc. Am., 82, 1018-1040, 1992.

Palano, M., Ferranti, L., Mattia, M., Monaco, C., Aloisi, M., Bruno, V., Cannavò, F., and Siligato, G.: GPS velocity and strain fields in Sicily and southern Calabria, Italy: updated geodetic constraints on tectonic block interaction in the central Mediterranean, J. Geophys. Res., 117, B07401, doi:10.1029/2012JB009254, 2012.

Sobol', I. Y. M.: On sensitivity estimation for nonlinear mathematical models, Mat. Model., 2, 112-118, 1990.

Solaro, G., Acocella, V., Pepe, S., Ruch, J., Neri, M., and Sansosti, E.: Anatomy of an unstable volcano from InSAR: Multiple processes affecting flank instability at Mt. Etna, 1994-2008, J. Geophys. Res., 115, B10405, doi:10.1029/2009JB000820, 2010.

Taylor, J. R.: Introduction to Error Analysis, 2nd Ed., University Science Books, 327 pp., Sausalito CA, 1997.

Trasatti, E., Cianetti, S., Giunchi, C., Bonafede, M., Piana Agostinetti, N., Casu, F., and Manzo, M.: Bayesian source inference of the 1993-1997 deformation at Mount Etna (Italy) by numerical solutions, Geophys. J. Int., 177, 806-814, 2009.

Tuvè, T., D'Amico, S., and Giampiccolo, E.: A new MD-ML relationship for Mt. Etna earthquakes (Italy), Ann. Geophys.-Italy, 58, doi:10.4401/ag-6830, 2015. 